\title{
Occam's razor: What is the best approach for a lobectomy?
}

\author{
Alexander J. Sbrocchi, MD, and Chadrick E. Denlinger, MD
}

\footnotetext{
From the Division of Cardiothoracic Surgery, Department of Surgery, Medical University of South Carolina, Charleston, SC.

Disclosures: Authors have nothing to disclose with regard to commercial support.

Received for publication March 13, 2018; accepted for publication March 19, 2018; available ahead of print April $11,2018$.

Address for reprints: Chadrick E. Denlinger, MD, Division of Cardiothoracic Surgery, Department of Surgery, Medical University of South Carolina, 114 Doughty St, Charleston, SC 29425 (E-mail: denlinge@ musc.edu). J Thorac Cardiovasc Surg 2018;156:363-4 $0022-5223 / \$ 36.00$

Copyright (C) 2018 by The American Association for Thoracic Surgery https://doi.org/10.1016/j.jtcvs.2018.03.055
}

The question regarding an optimal surgical approach for early-stage lung cancers is perfect for open debate because of the lack of quality comparative data and the presence of strong opinions and absolute convictions regarding each surgeon's favorite approach. In this issue of the Journal, Upham and Onaitis ${ }^{1}$ provide an excellent review of the different surgical approaches for lobectomies, including open thoracotomy, video-assisted thoracoscopic surgery (VATS), and robotically assisted thoracoscopic surgery. Although the criterion standard established by Ginsburg is an open thoracotomy, nonrandomized retrospective reviews have demonstrated slightly better outcomes for patients treated with VATS for early-stage tumors than for patients undergoing a thoracotomy, along with better tolerance of chemotherapy for patients requiring adjuvant chemotherapy. $^{2-4}$ Surgeons comfortable with VATS tout such benefits as fewer complications, less postoperative pain, and a diminished incitement of inflammatory cytokines, all of which can contribute to superior oncologic outcomes. On the other hand, surgeons well grounded in an open approach point out a selection bias, under which patients with small, peripheral tumors are offered VATS and patients with large, central tumors undergo a thoracotomy, as the greatest factor leading to improved outcomes with VATS. Robotically assisted surgery advocates point out similar outcomes to VATS — and they can do the operation while sitting in the corner. Although Upham and Onaitis ${ }^{1}$ make many important statements, one particularly germane comment is that no surgeon has equipoise, which would allow prospective randomization of patients in a trial comparing the 3 surgical approaches. Unfortunately, this means that our current quality of data may be as good as it will ever be.

The rule of Occam's razor states that entities should not be multiplied unnecessarily, or that one should choose the simplest option when all options are equal. In our practice, we perform resection of the overwhelming majority of

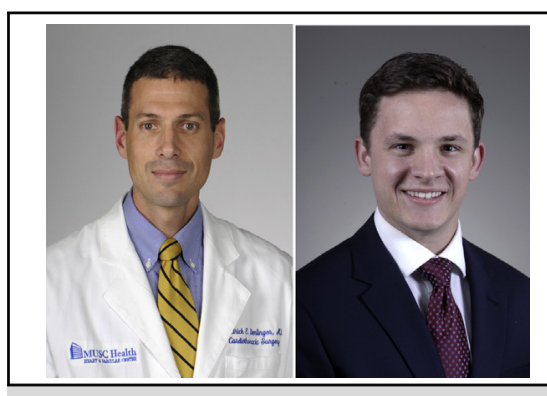

Chadrick E. Denlinger, MD (left), and Alexander J. Sbrocchi, MD (right)

Central Message

One must choose the anatomic resection that limits morbidity while limiting hospital cost and days spent in the hospital. With these outcomes being equal, one should choose the simplest option.

See Article page 365 .

clinical stage I cancers with VATS, because we believe in the oncologic equivalence of all approaches and we also believe in a reduction in complications, a reduction in length of hospital stay, and a faster return to work. Furthermore, our system, with which we have become comfortable as an academic center, is to use the VATS approach to facilitate resident education by having the attending set up the necessary exposure and then allowing the resident to do the case. This is the simplest approach in our program, but the necessary components of this approach are a confident attending and a capable trainee. Some previous graduates of our program have gone on to train other residents in the VATS approach at their respective programs, whereas others have migrated to robotically assisted thoracoscopic surgery because they were not working with residents and found it difficult to perform VATS single-handedly. We all develop an approach that works well in our own system, and it may be detrimental to patient care for us to assume that any particular approach is most appropriate in everyone's system.

\section{References}

1. Upham TC, Onaitis MW. Video-assisted thoracoscopic surgery versus robotassisted thoracoscopic surgery versus thoracotomy for early-stage lung cancer. J Thorac Cardiovasc Surg. 2018;156:365-8. 
2. Ginsburg RJ, Rubenstein LV. Randomized trial of lobectomy versus limited resection for T1N0 non-small cell lung cancer. Lung Cancer Study Group. Ann Thorac Surg. 1995;60:615-23.

3. Whitson BA, Groth SS, Duval SJ, Swanson SJ, Maddaus MA. Surgery for earlystage non-small cell lung cancer: A systematic review of video-assisted thoraco- scopic surgery versus thoracotomy approaches to lobectomy. Ann Thorac Surg 2008;86:2008-16; discussion 2016-8.

4. Petersen RP, Pham DK, Burfeind WR, Hanish SI, Toloza EM, Harpole DH Jr, et al. Thoracoscopic lobectomy facilitates the delivery of chemotherapy after resection for lung cancer. Ann Thorac Surg. 2007;83:1245-9; discussion 1250. 